\title{
Impact of Corporate Social Responsibility on the Organisational Performance - A Study With Reference to Select Companies in Chennai City - Reviews and Conceptual Frame Work
}

\author{
K. Dr. S. Raja ${ }^{1}$, Dr. M. Ganesan @ Kanagaraj ${ }^{2}$, K. Guru ${ }^{3}$ \\ ${ }^{1}$ Assistant Professor, Department of Management Studies, \\ SRM Valliammai Engineering College. \\ ${ }^{2}$ Assistant Professor, Department of Management Studies, \\ SRM Valliammai Engineering College. \\ ${ }^{3}$ Assistant Professor, Department of Management Studies, \\ SRM Valliammai Engineering College.
}

\section{INTRODUCTION}

Corporate Social Responsibility (CSR) is a management concept where by the companies integrates social and environmental concerns in their business needs, operations and interactions with their stakeholders. Corporate social responsibility is important to both consumers and company's .CSR is generally understood as being the way through which a company achieves a balance of economic, environmental and social imperatives, while at the same time it also helps in addressing the expectations of shareholders and stakeholders. A properly implemented CSR concept can bring along a various variety of competitive advantages, such as enhanced access to capital and markets, increased sales and profits, operational cost savings, improved productivity and quality, efficient human resource base, improved brand image and reputation, enhanced customer loyalty, better decision making and risk management processes. In this sense it is important to draw a distinction between CSR, which can be a strategic business management concept, and charity, sponsorships or philanthropy. Often, companies that adopt CSR programs have grown their business to the point where they can give back to society Even though the latter can also make a valuable contribution to poverty reduction, will directly enhance the reputation of a company and strengthen its brand, the concept of CSR clearly goes beyond that. It refers to practices and policies undertaken by corporations that are intended to have a positive influence on the world. CSR is generally understood as a strategic initiative that contributes to a brand's reputation. CSR is titled to aid an organization's mission as well as serve as a guide to what the company represents for its consumers. Business ethics is the part of applied ethics that examines ethical principles, moral and ethical problems that can arise in a business environment. Organizations in India have been quite sensible in adopting CSR initiatives and integrating them into their business processes. It has become progressively projected in the Indian corporate setting because the organizations have recognized that besides growing their businesses, it is also important to shape responsible, valuable and supportable relationships with the community at large.

\section{SCOPE OF SOCIAL RESPONSIBILITY}

Social responsibility objectives need to be built into corporate strategy of business rather than merely be statements of good intentions. Instead of seeking to maximize profit generally, the end result should be satisfactory level of profit which 
is compatible with the attainment of a range of social goals. Social responsibility involves more than just maximizing profits for the shareholders; it is also about creating positive changes and making valuable contributions to the stakeholders such as the local community, customers, and staff. In other words, the social responsibility is both profit-oriented and socially responsible as these companies seek to make financial gains, and at the same time, aim to improve the wellbeing of the community. Moreover, it includes customer satisfaction, truthfulness in advertising, completeness and clarity of labelling and packaging. Many of these considerations are important already from a marketing point of view. In doing so, the businesses engage in the voluntary initiatives with the aims of improving in various areas ranging from the social to environmental aspects of the society.

The concept of social responsibility is considered to be the highest level of involvement between the company and the community in which it operates. Environmental aspects of production, covering pollution control in the conduct of business operations, prevention or repair of damage to the environment resulting from processing of natural resources and the conservation of natural resources. It involves community activities, health-related activities, education and the arts and other community activity disclosures.

Corporate social objectives are to be found in the abatement of the negative external social effects of industrial production, and adopting more efficient technologies to minimize the use of irreplaceable resources and the production of waste.

\section{NEED FOR THE STUDY}

Corporate Social Responsibility (CSR) is when a company operates in an ethical and sustainable way and deals with its environmental and social impacts. This means a careful consideration of human rights, the community, environment, and society in which it operates. It's incredibly important that your company operates in a way that demonstrates social responsibility. CSR helps companies further develop the commitment and loyalty of their customers and employees as well as to increase sales and engage in new business activities although it's not a legal requirement, it's seen as good practice for you to take into account social and environmental issues. By embracing CSR, you stand out from competitors in your industry. You establish yourself as a company committed to going one step further by considering social and environmental factors. There are also a range of benefits for your employees when you embrace CSR. Your workplace will be a more positive and productive place to work, and by promoting things like volunteering, you encourage personal and professional growth which helps the organization to be unique. Being socially responsible can strengthen both a company's brand and image. When employees engage in social good activities, it is proven that they become more innovative and collaborative. A lot of skills can be developed when taking part in any kind of CSR activity and beyond this, employees are able to learn about potential clients, develop their communication skills, improve leadership and gain invaluable local insights. In turn, these new skills can develop within the workforce and allow the company to flourish within its market. If the employees are happy, their work will be of a higher quality.

\section{SCOPE-OF-THE-STUDY}

Successful businesses create an organizational culture that encourages employees to feel dedication and commitment to the company. One way to do that is through social responsibility initiatives, which allow individuals to make a difference through their jobs while they earn their paychecks. Corporate social responsibility projects give employees that invaluable feeling of making a difference, and can have other 
positive effects for your business as well. CSR may be approached as a management initiative that tends to improve organizational performance. Thus, managers need to identify which CSR investments provide the highest value. According theoretical framework, CSR activities are focused on the achievement of three major objectives. The company-related objective includes financial and marketing goals, while the stakeholders-related objective is concerned with the interests of employees, customers, suppliers and business partners finally, the society-related objective covers the issues associated with the environment, society and government. A strong CSR initiative is a key component to improve your company's reputation and help position you as an ethical and responsible alternative to your competitors. It serves to create and sustain trust between your company and your clients. Thus, attracting new business/partnerships, reinforcing existing relationships, and increasing market share

\section{RESEARCH GAP}

Whether the financial performance is related with CSR activities? How firms will behave in these domains under different performance gaps situations. CSR activities usually involve lower risk-taking than Research and Development or internationalization behaviors, we assume that underperformance in the past will increase CSR activities and underperformance in the future will decrease such practices. Besides, we are interested in whether the value of financial performance will influence the impacts of different performance gaps on CSR activities. First, we did not incorporate firms' choice among high risk-taking behaviors such as Research and Development actions and less risk-taking behaviors such as CSR practices into a framework.

\section{OBJECTIVES OF THE STUDY}

1) To investigate the relationship between corporate social responsibilities and HR Practices.

2) To investigate the relationship between corporate social responsibilities and Job satisfaction

3) To investigate the relationship between corporate social responsibilities and Employer Branding

4) To investigate the relationship between corporate social responsibilities and stakeholders advantage.

5) To investigate the relationship between corporate social responsibilities and Environmental factors.

6) To investigate the relationship between corporate social responsibilities and corporate governance. 


\section{CONCEPTUAL FRAMEWORK OF CSR}

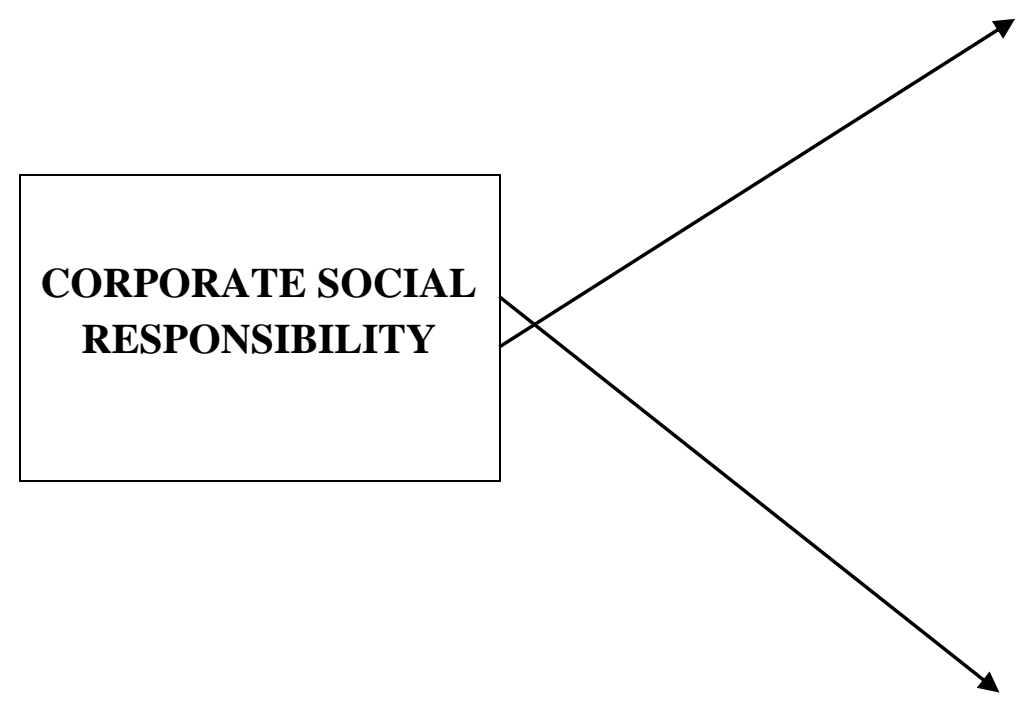

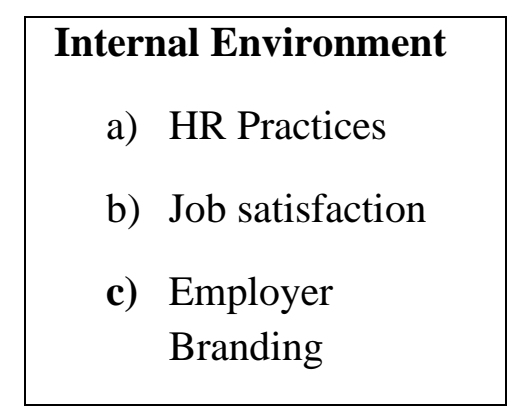

\section{External Environment}

a) Stakeholders advantage

b) Environmental Factors

c) Corporate Governance

\section{Relationship between CSR and HR Practices -} Review

Es-SaadiaAoula et.al (2013), discussed in a study the practices of human resources management in the promotion and development of CSR within the organizations. The study emphasized that in the fast changing working world, there have been changes in the employment relationship between employer and employee. This has resulted in an internal social responsibility between employer and employee relationship.

Borut Milfelner et.al (2012), in an exploratory study tried to establish a relationship between Social Responsibility (SR) and human resource management (HRM) and the influence of SR and HRM on organizational performance. The study is based on primary data and relevant statistical tools were applied to analyse the data collected. There are three inferences made from the study. First, the relationship between SR and HRM is strong and positive. Second, HRM has a positive impact on organizational learning and growth. Third, HRM seems to be affective only if it is oriented towards higher employee satisfaction and employee's loyalty. In such way it enables higher employee productivity which in turn results in better organizational performance.

\section{Relationship between CSR and Job satisfaction - Review}

Joash Mokamba Keraita et.al (2013), in an empirical study investigated the influence of internal CSR practices such as Training, Safety, Workplace Diversity and Work-Life balance on employee commitment. The results of the study identified that element of Internal CSR, namely; training, safety, work place diversity and work life balance correlated positively with employee commitment. The findings also emphasised that when banks perform in an ethical manner, such as fair, trustworthy, and unbiased bank procedures and also if the banks treat the employees with 
dignity and respect, the employees feel obliged to repay the bank with high levels of commitment.

Baptiste Bourdeau et.al (2013), in an empirical study demonstrated that a reputation associated with CSR influence employees' satisfaction, organizational commitment and employee turnover. The study is based on primary data and statistical measures such as correlation and regression was used to test the significance among the variables. The findings of the study showed that CSR indirectly improves organization's employee retention. It is also a factor of attraction and motivation of talented employees and it lowers absenteeism. A company always leads to increased satisfaction by improving the attitude of its employees and satisfied employees always result in better profitability and productivity.

\section{Relationship between CSR and Employer Branding - Review}

Chitramani et.al (2013) in a descriptive study highlighted that companies in IT industry have gained branding unconsciously rather than as 'well-thought plan'. Companies such as Infosys, Wipro and TCS had started their career in a humble way and created a place for themselves by setting a vision as 'middle-class turning into millionaires', as an opening for confident and inventive entrepreneurs and by providing training for fresh graduates. They focused more on creating a congenial and productive workplace, leading to happy employees. This consistent and family oriented approach of the companies raises the image of their products and their institution as well.

Majid Khan et.al (2013), in an exploratory study aimed to identify the impact of CSR on corporate reputation in developing country based on primary sources. The findings of the study pointed out that four main dimensions of CSR - environment oriented responsibilities, customer oriented responsibilities, community oriented responsibilities, and legal responsibilities positively influence the corporate reputation thereby increasing the organizational performance, of the company. Further it was highlighted that company image is considered as one of the important criteria for growth and that taking up CSR activities does help to build and maintain the reputation of the organization.

\section{Relationship between CSR and Stakeholders Advantage - Review}

James M. Gathungu et.al (2013), in an exploratory study identified various CSR programmes that Standard Chartered Bank (SCB) engage in and evaluate their influence on the strategic planning and decisions of the company to attain its goals. The research is conducted through a case study and primary data were collected for this purpose. The study established that SCB involved in lot of CSR practices with its main focus on the 'Seeing is Believing' theme where the organization sponsored various eye ailments especially children and the elders. The employees are also made to participate as volunteers and this develops a sense of responsibility and belonging amongst them. The study also established that all the CSR programmes directly contribute to attainment of the strategic planning and decisions which lead to the overall better performance of the organization.

Vikas Choudhary et.al (2013), in a descriptive study identified various CSR activities performed by public sector banks in India. The study makes use of secondary sources such as annual reports and research articles of various authors for its data collection and analysis. The findings of the study revealed that the banking industry focused mainly on community and village development. The CSR activities included women and child care, girl child adoption, dairy and agriculture development, village learning centers, poverty eradication and support for physically challenged youth in addition to employment generation and farmer training. The study showed that the banks are 
socially responsible and have realized their role in contributing towards community development more than economic gain.

\section{Relationship between CSR and Environmental factors - Review}

Wanyama James Wafula (2012), in an inventive study denoted the global perceptions of social responsibility, and also the various factors influencing the organisation's decision to pursue Corporate Social Responsibility initiatives. The study is based on secondary data, collected from several reliable sources. The inferences made from the study showed that employees prefer working for organisations which care for their interest also. Mostly organizations took steps to protect their environment by using ecofriendly systems such as ensuring less paper usage through use of electronic mail.

Md. Mustafizur Rahman et.al (2013), in an exploratory research analysed the prospects of green banking practices taken up in the banking sector in Bangladesh. The study was mainly based on secondary data collected from annual reports and related articles. The findings of the research suggested that CSR plays an important role in protecting environment and it can be done through funding NGO's, contribute in adverse situations like natural disasters and frame policies and reports on Green banking.

\section{Relationship between CSR and Corporate Governance - Review}

Debabrata Chatterjee (2010), in a descriptive research analyzed the approach to corporate governance including structure and practices followed, corporate social responsibility activities and conduct of board committees of three different Indian companies such as Reliance industries Ltd, ITC Ltd and Infosys Technologies Ltd. The inferences made out of the study indicated that a sound corporate governance measures supports socially responsible acts of companies.
Manivannan Rethinam et al. (2013), in an empirical study examined the relationship between the legal, ethical-philanthropic and economical aspects of CSR and how they influence in understanding various stakeholders satisfy their needs. The findings of the study based on primary sources show that compliance with legal regulations, striving to be ethical along with improving profits of the company is considered as healthy by stakeholders. The findings also highlighted that these are primarily the motivational factors that influence an organization to take up CSR and that younger stakeholders are more socially conscious and expect the organizations to act responsibly.

\section{CSR approaches, drivers and barriers in India}

It has been suggested that there are four models of social responsibility that operate in India:

1. The ethical (Gandhian) model

2. The statist (Nehruvian) model.

3. The liberal (Friedman) model.

4. The stakeholder (Freeman) model (Balasubramanian et al., 2005; Kumar et al., 2001).

Gandhi, Nehru, Friedman, and Freeman respectively were champions of these four models. In the ethical model the focus is on ,",voluntary commitment by companies to public welfare ${ }^{\text {eeee }}$, in the Statist model, ,,,state ownership and legal requirements determine corporate responsibilities $^{\text {eeee }}$, in the liberal model ,,,corporate responsibilities are limited to private owners ${ }^{\text {ecee }}$, and in the stakeholder model ,,,companies respond to the needs of stakeholders - customers, employees, communities, etc. ${ }^{\text {eee }}$ (Kumar et al., 2001,). Since the liberalization of the Indian economy in 1991, western-style ethical stances are being promoted hence even though the ethical, statist, and stakeholder models may be ,,,idealized ${ }^{\text {eeee }}$, the liberal (Friedman) model may be more influential in India, according to some authors (Balasubramanian et al., 2005). It is also noted that while these interpretations, or perceptions, help to clarify different approaches, it 
is important to understand that they are not mutually exclusive (Balasubramanian et al., 2005). Considering institutional changes, particularly to economic sectors, firms in Asian countries can report overlaps between two or more approaches, and in some cases, multiple orientations to these four models. Researchers have found that there is a definite trend in India towards looking at CSR in a positive manner (Narwal and Sharma, 2008; Reddy, 2006). There was a perception earlier on was that firms ${ }^{\text {ee }}$ CSR activities were not motivated by the desire for social service, but was instead motivated by the desire to avail themselves of tax exemptions and other government incentives and therefore society did not really trust business (Narwal and Sharma, 2008; Singh et al., 1980). This skeptical viewpoint is increasingly being replaced by a more objective viewpoint as businesses start to undertake CSR activities voluntarily (Narwal and Sharma, 2008). Post-liberalization, the Indian government, along with NGOs and the media are becoming agents of change with regard to the CSR activities of firms (Narwal and Sharma, 2008). In fact, in a study of companies from 21 emerging markets, Baskin (2006) found that in these markets (particularly South Africa, Brazil, India, and parts of Eastern Europe), CSR was more developed than commonly thought, often exceeding standards in some high-income countries. Even though CSR in India may be in a more advanced state than previously thought, some studies suggest that much improvement is needed in how CSR strategies are implemented and integrated within Indian firms. For example, Arora and Puranik (2004) concluded that even though several companies in India have climbed on to the CSR bandwagon and are engaged in causes like health care, education, empowerment of women, microcredit and rural development, CSR seems to be in a confused state in the country. Individual companies define CSR in their own ways, with the end result that activities undertaken in the name of CSR are merely philanthropy or an extension of it
(Arora and Puranik, 2004). Baskin (2006) found that even though CSR was more developed than previously thought in emerging market countries including India, it was found to be less embedded in corporate strategies and less pervasive than in higher-income countries. The study also found a wide divergence between emerging market leaders and laggards.

\section{Corporate Social Responsibility Voluntary Guidelines 2009}

In order to assist the businesses to adopt responsible governance practices, the Ministry of Corporate Affairs has prepared a set of voluntary guidelines which indicate some of the core elements that businesses need to focus on while conducting their affairs. These guidelines have been prepared after taking into account the governance challenges faced in our country as well as the expectations of the society. The valuable suggestions received from trade and industry chambers, experts and other stakeholders along with the internationally prevalent and practiced guidelines, norms and standards in the area of Corporate Social Responsibility have also been taken into account while drafting these guidelines.

Fundamental Principle: Each business entity should formulate a CSR policy to guide its strategic planning and provide a roadmap for its CSR initiatives, which should be an integral part of overall business policy and aligned with its business goals. The policy should be framed with the participation of various level executives and should be approved by the Board. Core Elements: The CSR Policy should normally cover following core elements:

1. Care for all Stakeholders: The companies should respect the interests of, and be responsive towards all stakeholders, including shareholders, employees, customers, suppliers, project affected people, society at large etc. and create value for all of them. They should develop mechanism to actively engage with all stakeholders, inform them 
of inherent risks and mitigate them where they occur.

2. Ethical functioning: Their governance systems should be underpinned by Ethics, Transparency and Accountability. They should not engage in business practices that are abusive, unfair, corrupt or anti-competitive.

\section{Respect for Workers' Rights and Welfare:}

Companies should provide a workplace environment that is safe, hygienic and humane and which upholds the dignity of employees. They should provide all employees with access to training and development of necessary skills for career advancement, on an equal and nondiscriminatory basis. They should uphold the freedom of association and the effective recognition of the right to collective bargaining of labour, have an effective grievance redressed system, should not employ child or forced labour and provide and maintain equality of opportunities without any discrimination on any grounds in recruitment and during employment.

4. Respect for Human Rights: Companies should respect human rights for all and avoid complicity with human rights abuses by them or by third party.

5. Respect for Environment: Companies should take measures to check and prevent pollution; recycle, manage and reduce waste, should manage natural resources in a sustainable manner and ensure optimal use of resources like land and water, should proactively respond to the challenges of climate change by adopting cleaner production methods, promoting efficient use of energy and environment friendly technologies.

\section{Activities for Social and Inclusive} Development: Depending upon their core competency and business interest, companies should undertake activities for economic and social development of communities and geographical areas, particularly in the vicinity of their operations. These could include education, skill building for livelihood of people, health, cultural and social welfare etc., particularly targeting at disadvantaged sections of society.

\section{CONCLUSION}

In developing countries like India, corporate social responsibility plays an important role. A company gets all needed inputs from people and the environment. A company needs people's support to make money and people understand that and help that company in the form of purchasing company shares, supplying raw material and purchasing their product and services. Corporate social responsibility gives the company a high level of enthusiasm and selfconfidence because all the employees who work here at the company meet people directly and help them understand what they need. Chennai is one of the IT hubs in India. Here so many people working in software companies. The administration provides all the facilities required for all the employees working in the software company but they have too much workload. Corporate social responsibility reduces stress in the employee's space. The government also urges the company to adhere to the federation's social responsibility and the government orders companies to follow suit. Corporate social responsibility acts as a bridge between the public, the institution and the government which does many good things for people.

\section{REFERENCES}

[1]. Adam S. Maiga and Fred A. Jacobs (2005), Antecedents and Consequences of Quality Performance. Behavioral Research in Accounting: February 2005,Vol. 17, No. 1, pp. 111- 131.

[2]. Allen Richard S, Merlyn M Helms,Margaret B. Takeda, Charles S White, Cynthia White (2006). A Comparison Of Competitive Strategies in Japan and United State. S.A.M. Advanced Management Joumal: 71,1.,ABI/INFORM Global. 
[3].Atkinson, Helen. 2006. Strategy lmplementation: A Role for the Balanced Scorecard, Management Decision, Vol. 44. 10, pp. 1441 - 146041.

[4].Atmadja, Stanley. 2009. Making The Giant Leap, PT. Gramedia Pustaka Utama, Jakarta.

[5]. Arendt dan Brettel, 2010, Understanding the influance of corporate social responsibility on corporate identity, image, and firm performance, Management Decision, vol. 48.No. 10, 2010pp.1469-1492.

[6].Baldrige National Quality Program (2003), Education Criteria for Performance Excellent, www.quality.nist.gov

[7].Balthazard, Pierre A.Robert A Cooke,and Richard E. Potter, 2006, Dysfunctional Culture, Disfunctional Organization: Capturing The Behavioral Norms That Form Organizational Culture and Drive Performance, Journal of Managerial Psychology,volume 21, Number 8, pp.709732.

[8].Barney, J. B. and M. H. Hansen: 1994,,,Trust worthiness as a Source of Competitive Advantagee, Strategic Management Journal (WinterSpecial Issue) 15, 175-190.

[9].Barney, J.B. 2002, Gaining and Sustaining Competitive Advantage.2nd ed., PrenticeHall, Upper Saddle River. NJ.Barney, J.B. 1995.Looking inside for competitive advantage, Academy of Management Executive, vol. I, No.4, PP.4955. 